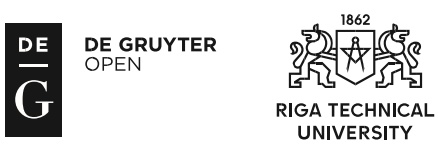

ISSN 2256-0394 (online)

ISSN 2256-0386 (print)

August 2017, 31, 30-43

doi: 10.1515/eb-2017-0016

https://www.degruyter.com/view/j/eb

\title{
MANAGING CAPABILITIES FOR SUPPLY CHAIN RESILIENCE THROUGH IT INTEGRATION
}

\author{
Valentas GRUŽAUSKAS ${ }^{1}$, Mantas VILKAS ${ }^{2}$ \\ ${ }^{1,2}$ Kaunas University of Technology, Lithuania \\ Corresponding author e-mail: valentas.gruzauskas@ktu.lt
}

\begin{abstract}
The trend for e-commerce, estimated population size to 11 billion by 2050 , and an increase in urbanization level to $70 \%$ is requiring to re-think the current supply chain. These trends changed the distribution process: delivery distances are decreasing, the product variety is increasing, and more products are being sold in smaller quantities. Therefore, the concept of supply chain resilience has gained more recognition in recent years. The scientific literature analysis conducted by the authors indicate several capabilities that influence supply chain resilience. Collaboration, flexibility, redundancy and integration are the most influential capabilities to supply chain resilience. However, the authors identify that the combination of these capabilities to supply chain resilience is under researched. The authors indicate that by combining these capabilities with the upcoming technologies of industry 4.0, supply chain resilience can be achieved. In the future, the authors are planning to conduct further research to identify the influence of these capabilities to supply chain resilience, to quantify supply chain resilience, and to provide further practices of industry 4.0 concept usage for supply chain resilience.
\end{abstract}

Keywords: 4th industrial revolution, flexibility, IT integration, redundancy, resilience, supply chain management.

JEL: L91, O14, O31.

\section{INTRODUCTION}

The e-commerce trend has led to new challenges for the industry. Today, consumers desire for personalized products, just-on-time to their doorstep, and with minimal costs. However, the challenge of shifting trends and the constant disturbances of the market increase the instability of the supply chain. Recent scientific literature amplifies the supply chain resilience problem and recommends various strategies to cope with the disturbances (Ambulkar, Blackhurst \& Grawe, 2015; Elleuch, Dafaoui, Elmhamedi \& Chabchoub, 2016; Gonçalves \& Chicareli, 2014; Kim, Chen \& Linderman, 2015; Mensah \& Merkuryev, 2014; Munoz \& Dunbar, 2015; Nikookar, Takala, Sahebi \& Kantola, 2014). There are different approaches to define and measure resilience in the supply chain. In summary, supply chain resilience defines the ability of the chain to cope with disturbances and maintain their original state (Croxton, 2010; 
Fiksel, 2007; Lengnick-Hall, Beck \& Lengnick-Hall, 2011; Zobel \& Cook, 2008). However, the resilience concept is still new and under researched. Moreover, due to the growing world's population, more people will live in urban regions, which will make the e-commerce supply chain even more complex (Food and Agriculture Organization, 2015). Constant traffic jams, weather conditions, IT malfunctions cause disturbances to the supply chain, which dramatically raises costs and increases the leadtime (Baylis et al., 2015). "The Last leg of the supply chain is least efficient, comprising up to $28 \%$ of the total logistics cost" (Lau, 2014). Supply chain resilience can be achieved by different capabilities of the supply chain (Ambulkar et al., 2015; Gonçalves \& Chicareli, 2014; Kim et al., 2015; Mensah \& Merkuryev, 2014).

Supply chain resilience capabilities have been analysed in the aspect of resilience; however, the field is still under researched. Nikkokar et al. (2014) stated that there is a significant gap between experiences and the expectations of practices for supply chain resilience. Elluech et al. (2016) amplified the necessity to develop resilience practices for optimal allocation of resources. One of the practices amplified is collaboration, which positively effects resilience - however, from a redundancy approach and not flexibility. Ambulkar et al. (2015) indicate the necessity to have flexibility and agility to effectively manage the infrastructure of the collaboration. The empirical evidence of Croxton et al. (2013) revealed that low collaboration, lack of excess capacity, and minimal flexibility are the major causes of ineffective supply chain resilience. Park's (2011) empirical evidence identified that resilience and redundancy practices positively affect supply chain resilience. However, the influence of the combination of these practices on supply chain resilience should also be considered. To effectively manage flexibility and redundancy, integration capability should also be addressed. Wieland \& Wallenburg (2013) identified that communicative and cooperative relationships have a positive effect on resilience, while integration does not have a significant effect. Without the capability to utilize information effectively, the high collaboration level is ineffective, because the collaboration becomes too complex and loses flexibility. However, Liu et al. (2013) indicated that IT integration capabilities can improve redundancy; however, they do not necessarily improve flexibility.

In summary, there are two approaches to achieve resilience. On the one hand, resilience can be achieved by reorganizing current resources quickly, which is a flexibility-based approach (Ponis \& Koronis, 2012). Another approach is to increase the commitment of the chain by finding more suppliers and increasing the inventory level, which is called redundancy or increasing the robustness of the chain (Leat \& Revoredo-Giha, 2013). Research analyses different capabilities that can help achieve supply chain resilience.

One of the most amplified capabilities is collaboration (Zhao, Liu, Zhang \& Huang, 2016; Bosona \& Gebresenbet, 2011; Kim et al., 2015; Wang, Gunasekaran, Ngai \& Papadopoulos, 2016). Collaboration is based on certain computability, commitment, 
and capabilities. The members of the chain must have certain characteristics, which would make the collaboration possible. These characteristics can be defined depending on the situation, e. g., geographical position, main industry, and so on. The commitment level of the collaboration members can provide different economical and competitiveness benefits. The collaboration can commit to share general information, share equipment, or make strategic plans with other collaboration members. The benefits and approaches to collaboration have been widely researched; however, the main research gap is that the most amplified resilience strategy is based on collaboration, which enables the supply chain members to share information and commitments and gain resilience. However, the strategy is based on unclear commitments and decreases the turnover rate of the working capital, because it recommends gaining flexibility by increasing redundancy (Zhao et al., 2016; Bosona \& Gebresenbet, 2011; Kim et al., 2015; Wang et al., 2016). A large number of members in the collaboration process can provide better efficiency levels in terms of costs; however, it limits the ability of the collaboration to cope with disturbances by increasing the complexity and limiting the visibility.

The majority of the research amplifies the necessity to make trade-offs in supply chain management (Esfahbodi, Zhang \& Watson, 2016; Morrison-Saunders \& Pope, 2013; Beckmann, Hielscher \& Pies, 2014; Seuring, 2013; Studies, 2012). However, only a few researches analyse how the combination of supply chain capabilities can influence resilience. Moreover, the development of innovative technologies is influencing the concept of supply chain capabilities. The major impact has been done by the development of industry 4.0 concept to the supply chain. This concept involves Internet of Things (IoT), which is responsible for information gathering, big data analytics (information processing), and autonomous vehicles (information utilization) (Swafford, Ghosh \& Murthy, 2008; Chen, Cheng \& Huang, 2013; Navickas \& Gruzauskas, 2016; Zhao et al., 2016; Klötzer \& Pflaum, 2015). Therefore, by identifying the main capabilities, which are responsible for supply chain resilience, and by limiting the trade-offs in the process by using innovative technologies, supply chain resilience can be achieved. Therefore, the goal of the paper is to analyse the essential capabilities, which can help achieve resilience, and to provide an IT-based approach to limit the trade-offs in the process. To accomplish this goal, a comprehensive literature analysis will be conducted and in the future, the proposed methodology will be validated by conducting an agent-based model of the supply chain. The following objectives will be addressed in this paper:

1. Analyse the concept of supply chain resilience and capabilities to achieve resilience;

2. Indicate the essential innovations of the 4th industrial revolution to supply chain;

3. Develop a strategy of how to use the innovative technologies to limit the tradeoffs in supply chain management. 


\section{SUPPLY CHAIN RESILIENCE CONCEPT AND CAPABILITIES}

Firstly, it is important to define what exactly supply chain resilience is before analysing the capabilities that can influence resilience in the chain. Resilience concept has been analysed not only in the context of supply chain but at a more general organization level. Fiksel (2007) describes resilience as the capacity of an enterprise to survive, adapt, and grow in the face of turbulent change. Lengnick-Hall et al. (2011) identify the firm ability to effectively absorb and develop situation-specific responses to ultimately engage in transformative activities to capitalize on distributive surprises that potentially threaten organization survival. Other researches identify the resilience concept in the supply chain context. Zobel \& Cook (2008) amplify also the ability for a supply chain to reduce the probability of destruction by identifying upcoming risks: "Supply chain resilience is the ability of a supply chain system to reduce the probabilities of a disruption, to reduce the consequences of those disruptions once they occur, and to reduce the time to recover normal performance". Ponis \& Koronis (2012) provide an even more widely adapted description of supply chain resilience: "The ability to proactively plan and design the Supply Chain network for anticipating unexpected disruptive (negative) events, respond adaptively to disruptions while maintaining control over structure and function and transcending to a post-event robust state of operations, if possible, more favourable than the one prior to the event, thus gaining competitive advantage". Researchers differently describe the supply chain resilience concept depending on the situation and the context. The analysis of the paper will focus on the resilience concept according to Zobel \& Cook (2008) because it involves flexibility and redundancy approaches to resilience.

Table 1. Literature Review and Conceptualization of Supply Chain Resilience

\begin{tabular}{|l|l|}
\hline \multicolumn{1}{|c|}{ Topic } & \multicolumn{1}{c|}{ Author } \\
\hline Analyses supply chain risk, vulnerabilities, and disruptions & Elleuch et al., 2016 \\
\hline Defines supply chain resilience & $\begin{array}{l}\text { Ponis \& Koronis, 2012 } \\
\text { Jüttner \& Maklan, 2011 }\end{array}$ \\
\hline IT approach to supply chain resilience & $\begin{array}{l}\text { Klötzer \& Pflaum, 2015 } \\
\text { Zobel \& Cook, 2008 }\end{array}$ \\
\hline Defines macro or strategic view of resilience & $\begin{array}{l}\text { Demmer, Vickery \& Calantone, 2011 } \\
\text { Mensah \& Merkuryev, 2014 }\end{array}$ \\
\hline Analyses supply chain risk, vulnerabilities, and disruptions & Leat \& Revoredo-Giha, 2013 \\
\hline Analyses supply chain design relationship with resilience & Kim et al., 2015 \\
\hline $\begin{array}{l}\text { Analyses the impact of capabilities on supply chain } \\
\text { resilience }\end{array}$ & $\begin{array}{l}\text { Gonçalves \& Chicareli, 2014 } \\
\text { Croxton, 2010 } \\
\text { Proper, 2011 }\end{array}$ \\
\hline
\end{tabular}

The context of supply chain resilience has been analysed from different perspectives; however, it is still under research with only a limited amount of publications. The bibliometric analysis of the Web of Science by using the key word "supply chain resilience" indicated a total of 388 publications, which in the period of 
2001-2008 consisted of only 16 publications related to supply chain content. From 2009 , the publication quantity increased to 14 per year, and in 2016 - to 109 per year. The bibliometric analysis identifies that the concept of supply chain resilience is only gaining recognition and lacks theoretical and empirical evidence. Table 1 demonstrates the research done in the context of supply chain resilience, which covers different aspects of supply chain resilience. There are many researches which have analysed these aspects of the supply chain, therefore Table 1 indicates the most diverse of the research. Several authors have conducted a deep literature review related to resilience.

Elleuch et al. (2016) conducted a literature review based on resilience and vulnerability and identified that optimal allocation of resources needs to be more developed for selecting efficient resilient supply chain with the trade-offs between vulnerability reduction and resilience capacities enhancement, because there is lack of practices for supply chain resilience achievement. The research limit in the practice used for supply chain resilience has been analysed. Mensah \& Merkuryev (2014) identified the main factors that are essential for supply chain resilience - decision making, strategy, and tactics (DMST) - and proposed practices to gain resilience: Lean production with JIT delivery and low inventory, Six sigma supply chain, Increasing SC flexibility, and Developing a strong corporate culture. Nikookar et al. (2014) indicated that there are significant gaps between experiences and expectations of the implementation performance of resilient practices. Therefore, there is a need to understand the approaches to supply chain resilience to provide better orientation to practices. Ponis \& Koronis (2012) analysed the approaches to supply chain resilience and indicated that most grounded antecedents of supply chain resilience are agility, flexibility, velocity, visibility, availability, redundancy, mobilization of resources, collaboration, and supply chain structure knowledge. They proposed a framework consisting of flexibility, collaboration, and agility; however, they did not consider IT integration and visibility, which are essential capabilities of industry 4.0 concept. The proposed framework lacks empirical evidence; therefore, the validity of it is also questioned.

Christopher \& Peck (2004) analysed the supply chain resilience concept and focused on the supply chain capabilities to deal with risk by promoting flexibility and agility; however, they did not consider redundancy and IT integration aspects of the supply chain. The collaboration benefits, commitments and compatibility issues are widely researched and provide theoretical and empirical evidence for the benefits of collaboration. Leat \& Revoredo-Giha (2013) reduced supply chain vulnerability through horizontal collaboration amongst producers, and vertical collaboration with the processor and retailer. The collaboration generated greater security of the supply of an assured quality, improved communication with suppliers, and reduced demand risk as they could assure the consumers on quality, animal welfare, and product provenance; however, this particular research amplified more the supply chain design and redundancy concept and did not consider flexibility. Gonzalez-Feliu et al. (2013) used a simulation approach to promote the collaboration and indicated that it is necessary to develop decision support systems that involve all the decision makers concerned, by 
preparing them to be predisposed to discussion and convergence through consensus. The decision support system for information gathering and processing is not enough, there is a need to optimize the capability of the utilization of the information, which would increase the resilience of the supply chain.

There are also other researches that amplified the collaboration benefits (Zhao et al., 2016; Bosona \& Gebresenbet, 2011; Kim et al., 2015; Wang et al., 2016). The collaboration approach is based on a theoretical aspect of improvement of the efficiency of the chain, e. g., partial freight collection, information sharing, etc. However, from a practical point of view, the implementation of the collaboration frameworks is limited and lacks the research of how supply chain capabilities influence collaboration. The majority of research listed identifies how it is possible to achieve supply chain resilience by increasing the redundancy and commitments of the chain; however, Ambulkar et al. (2015) indicate that supply chain disruption orientation alone is not enough for a firm to develop resilience. Supply chain disruption-oriented firms require the ability to reconfigure resources or have a risk management resource infrastructure to develop resilience.

Table 2. Empirical Evidence of Supply Chain Resilience

\begin{tabular}{|l|l|}
\hline \multicolumn{1}{|c|}{ Topic } & \multicolumn{1}{c|}{ Author } \\
\hline Measures supply chain resilience & Soni, Jain \& Kumar, 2014 \\
& Munoz \& Dunbar, 2015 \\
& Mahdi, Vahid \& Hamid, 2015 \\
& Croxton, Pettit, Croxton \& Fiksel, 2013 \\
& Spiegler, Naim \& Wikner, 2012 \\
\hline Defines resilience practices & Nikookar et al., 2014 \\
& Pettit, Croxton \& Fiksel, 2013 \\
& Fakoor, Olfat, Feizi \& Amiri, 2013 \\
& Liu et al., 2013 \\
& Cabral, Grilo \& Cruz-Machado, 2012 \\
& Prajogo \& Olhager, 2012 \\
& Park, 2011 \\
& Wu, Yeniyurt, Kim \& Cavusgil, 2006 \\
\hline Defines macro or strategic view of resilience & Childerhouse, Kang, Huo \& Mathrani,2016 \\
& Ambulkar et al., 2015 \\
& Berle, Norstad \& Asbjørnslett, 2013 \\
& Wieland \& Wallenburg, 2013 \\
& Christopher \& Peck, 2004 \\
\hline
\end{tabular}

Table 2 shows empirical evidence related to the capabilities of supply chain. Park (2011) analysed the influence of flexible and redundant supply chain practices on supply chain resilience. He defined supply chain practices as flexible and redundant, which consisted of information sharing, security compliance, extent of collaboration, contingency planning, safety stock, and slack capacity. The empirical evidence mainly analysed how flexibility and redundancy practices influence the capabilities of supply chain resilience. The results indicated that both supply chain resilience practices are 
positively associated with the capabilities of supply chain resilience. The more firms implement supply chain resilience practices, the more likely they are to formulate the capabilities of supply chain resilience. However, this research did not consider the combination of flexibility and redundancy practices influence on supply chain resilience. Croxton et al. (2013) analysed supply chain resilience relationship with supply chain performance. The research developed a measurement tool titled the "Supply Chain Resilience Assessment and Management" (SCRAM). Data gathered from seven global manufacturing and service firms was used to validate SCRAM, using qualitative methodology with 1,369 empirical items from focus groups reviewing 14 recent disruptions. Their empirical evidence concluded that firms in this study reported capability strengths in the areas of Market Position, Recovery, and Financial Strength. However, consistent reports of low Collaboration, lack of excess Capacity, and minimal Flexibility raised serious concerns (Croxton et al., 2013). This research provides evidence that the collaboration, redundancy and flexibility capabilities must be addressed in a more specific way in order to better utilize them for supply chain resilience. Wieland \& Wallenburg (2013) analysed the influence of relational competencies on supply chain resilience. They identified that communicative and cooperative relationships have a positive effect on resilience, while integration does not have a significant effect. Integration in this research referred to the process of combining efforts "to integrate supplier and customer information and inputs into internal planning". Without the capability to utilize information effectively, the high collaboration level is ineffective, because the collaboration becomes too complex and loses flexibility.

Hefu et al. (2013) analysed the influence of flexible IT infrastructure and IT assimilation capabilities on the firm's performance through absorptive and agility capabilities. The results strongly support that a firm's IT capabilities can help the firm improve its absorptive capacity. However, the results of this study do not support the hypothesis on the association of IT capabilities and supply chain agility. This empirical evidence indicates that IT capabilities influence the robustness of the supply chain or redundancy; however, they do not provide agility, which is a component of flexibility. The influence of IT capabilities on agility was limited, because the research did not consider the information utilization possibilities, which are possible with CPS or selfdriven vehicles.

Fang et al. (2006) analyzed how information technology improves the supply chain process. The evidence suggested that the investment in IT does not guarantee enhanced organizational performance. This study proposes that IT-enabled supply chain capabilities are firm-specific and hard-to-copy across organizations. Prajogo \& Olhager (2012) investigated the integrations of both information and material flows between supply chain partners and their effect on operational performance. They found that logistics integration has a significant effect on operations performance. Information technology capabilities and information sharing both have significant effects on logistics integration. However, they did not consider collaboration and resilience aspects. Wang et al. (2016) analyzed the interpersonal relationship to supply 
chain integration through interorganizational cooperation. The literature analysis indicated that interpersonal relationship including personal affection, communication, and credibility have a positive influence on supply chain integration, and these links are mediated by interorganizational relationships including trust, commitment, and power. However, this research did not provide empirical evidence and did not consider supply chain resilience.

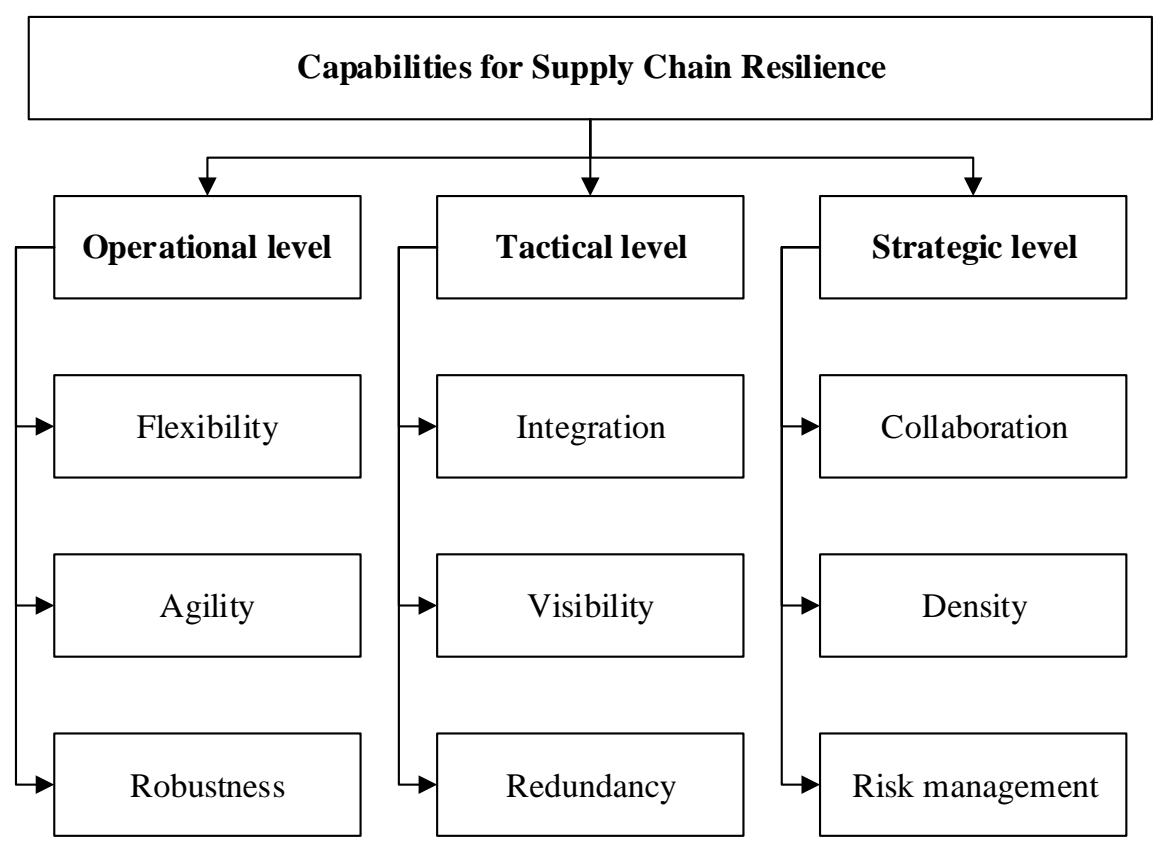

Fig. 1. Capabilities for achieving supply chain resilience.

Goncalves \& Chicareli (2014) identified capabilities that make the largest contribution to resilience flexibility (supplier, product, process, transportation), collaboration (information sharing, joined decision making, working together), structure of chain (physical, information), and agility (visibility, velocity). Goncalves and Chiricareli amplifies that empirical studies about most suitable management capabilities before, during a after a distribution in the supply chain is needed. Figure 1 lists the main capabilities of the supply chain, which are categorized based on approaches to supply chain resilience. These capabilities cover the approaches to supply chain resilience covered before. The main capabilities that are necessary for integration of industry 4.0 concept are collaboration, flexibility, redundancy, and integration.

The collaboration benefits have a theoretical and empirical background; however, there is a lack of practical implementation and management aspect of the capability. Flexibility is the ability of the chain to cope with disturbances much faster and return to its original state, which benefits have been proved. The redundancy capability 
mainly focuses on increasing supplier number or inventory, which created robustness for supply chain and increases the costs. Lastly, the integration capability should be addressed to provide a supply chain resilience approach through the industry 4.0 concept.

\section{MANAGING SUPPLY CHAIN RESILIENCE BY USING INDUSTRY 4.0 CONCEPT}

The development of industry 4.0 concept is important to supply chain resilience due to several reasons. Firstly, the world's population is expected to reach nine billion by 2050 (Parfitt, Barthel \& Macnaughton, 2010). Secondarily, the urbanization will continue at an accelerated pace, and about 70 percent of the world's population will be urban (compared to 49 percent today) (Food and Agriculture Organization, 2015). The third reason is because of the trend for e-commerce has required the enterprises to distribute high variety and low quantity products quickly and cheaply. And, lastly, the urban logistics costs consist of $28 \%$ from the total logistic costs, which is the least efficient part of the supply chain (Lau, 2014). All these trends suggest that the supply chain should be more focused on urban logistics; however, the urban logistics is a complex distribution method, which involves multiple disturbances that consist of weather conditions, traffic jams, IT malfunctions, etc. To cope with these disturbances and maintain low costs, a fast responsive supply chain should be developed. Therefore, the capabilities of redundancy, flexibility, collaboration, and integration should be addressed in a more detailed way.

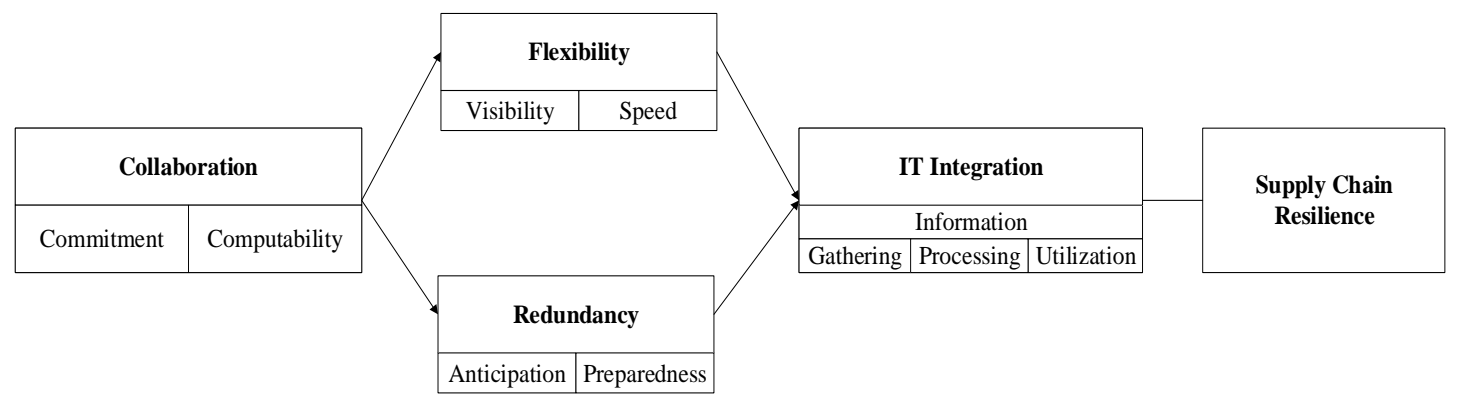

Fig. 2. Capabilities integration with industry 4.0 concept for supply chain resilience.

Figure 2 indicates the approach of these capabilities to supply chain resilience. There are certain commitments and computability issues that should be solved in the chain. The combination of these compatibilities in the chain requires a certain type and activities of organization to conduct a collaborative supply chain. Moreover, the commitments should be discussed among the members to make an efficient collaboration. Flexibility is based on the visibility of the supply chain and speed to cope with disturbances and return to its original state, while redundancy focuses on the anticipation and preparedness of upcoming disturbances. However, too much preparedness (e.g., inventory level) can cause the supply chain to be inefficient. 
Therefore, there should be an optimal relationship between these capabilities. Lastly, to provide real-time and fast response time to disturbance, IT integration must be implemented in the whole capabilities management process. This chapter will focus more on the IT integration capability by focusing on industry 4.0 concept.

Swafford et al. (2008) indicated that IT integration enables a firm to tap its supply chain flexibility, which in turn results in higher supply chain agility and ultimately higher competitive business performance. Since 2008, the IT integration concept has changed due to new innovative technologies development, which involves the industry 4.0 concept. Moreover, this particular reach did not consider resilience. Therefore, more research should be done in analysing the IT ingestion influence to supply chain resilience.

The industry 4.0 concept consists of several aspects. Firstly, it involves the Internet of Things concept, which identifies how information is gathered from the supply chain, which in its turn enables visibility. Chen et al. (2013) apply lean production and radio frequency identification (RFID) technologies to improve the efficiency and effectiveness of supply chain management. Experiments showed that the total operation time can be saved by $81 \%$ from the current stage to future stage with the integration of RFID and lean. However, information gathering is not enough to utilize the potential of the technology. Virtualization enables supply chain actors to monitor, control, plan, and optimize the business processes remotely and in real- time through the Internet, based on virtual objects instead of on-site observation (Verdouw, Wolfert, Beulens \& Rialland, 2015).

Furthermore, analytic approaches should be used to provide insights from the gathered information. Navickas \& Gruzauskas (2016) conducted a literature analysis on big data used for supply chain management. They indicated that big data analytics can provide competitiveness advantage to the supply chain. However, this research lacked empirical evidence and concrete practices, which would enable big data usage for supply chain. A more recent research by Zhao et al. (2016) indicated that there are very few studies regarding the integration of big data science and supply chain management. The IoT and big data concepts cover only part of the industry 4.0 concept. Recently, research has increased in the usage of cyber-physical systems for supply chain management. The emerging technology of Cyber-Physical Systems (CPS) promises new problem solutions in manufacturing, logistics, and SCM (Klötzer \& Pflaum, 2015). In the past, this concept focused only on production; however, new technologies require rethinking of the current supply chain.

The main idea of the CPS is that information can be utilized in a more efficient way, which would enable the supply chain to make real-time decisions. This can be accomplished by using autonomous vehicles, which would reorganize themselves based on the disturbances of the supply chain. The concept of autonomous vehicles has gained more recognition in recent years. One of the largest distribution companies indicated that autonomous vehicles can provide higher efficiency: "Traffic can flow faster and congestion can be reduced with autonomous driving. Using vehicle-tovehicle communication, autonomous systems can set high speeds and intelligently 
avoid busy routes. In addition, the all-too-familiar time limitations placed on freight trucks will be removed; they will be able to travel 24/7 without requiring driver rest time and - compared with today's driving - could achieve overall cost reductions in the region of $40 \%$ per kilometre" (DHL Trend Research, 2014). However, the usage of innovative technologies in the system of supply chain management causes the initial capital to raise dramatically. Therefore, the relationship between flexibility and redundancy must be addressed to find the optimal combination of required capital investments and the ability of the systems to reorganize effectively.

\section{CONCLUSION}

The extensive literature analysis indicated the lack of the understanding of the influence of combined capabilities on supply chain resilience. The influence of supply chain capabilities on resilience lacks theoretical grounding, empirical evidence, and practical implementation possibilities. Moreover, to identify the relationship between redundancies and flexibility to resilience, specific indexes should be created to measure the possible usage of these capabilities in supply chain management. Research has been done in the quantification of supply chain resilience; however, the model must address multiple criteria, and still a well-recognized index is not established (Munoz \& Dunbar, 2015).

The literature analysis approach to supply chain resilience concept, capabilities, and industry 4.0 indicated several future research areas which should be addressed: combination of different capabilities influence on supply chain resilience, supply chain resilience quantification, and empirical evidence which would identify the potential of cyber-physical systems usage in the supply chain.

In the future, the authors of the paper will make an agent-based model of the supply chain. The idea of the agent-based model is to define agents such as farmers, processing plants, warehouses, consumers, and pick-up points; then the relationship between the agents will be defined. This relationship will represent daily operations and decision such as route scheduling and demand forecasting. Daily operations will depend on IT integration level in the organizations. Two scenarios will be chosen, which will represent the usage of low innovative technologies and high innovative technologies. Moreover, criteria to begin collaboration and to end collaboration will be implemented. These criteria will depend on commitment and the computability dimensions of collaboration, and the decision will be based on supply chain resilience index. The main idea of the simulation is to represent how micro decisions impact macro environment in the long-run. However, the agent-based model, which represents real world environment, is difficult to implement and further research is required to validate the proposed strategy fully. 


\section{REFERENCES}

Ambulkar, S., Blackhurst, J., \& Grawe, S. (2015). Firm 's resilience to supply chain disruptions : Scale development and empirical examination. Journal of Operations Management, 33-34, 111-122. http://doi.org/10.1016/j.jom.2014.11.002

Baylis, J., Grayson, M. E., Lau, C., Gerstell, G. S., Scott, B., \& Nicholson, J. (2015). Transportation Sector Resilience. National Infrastructure Advisory Council.

Beckmann, M., Hielscher, S., \& Pies, I. (2014). Commitment Strategies for Sustainability: How Business Firms Can Transform Trade-Offs Into Win-Win Outcomes. Business Strategy and the Environment, 23(1), 18-37. http://doi.org/10.1002/bse.1758

Berle, Ø., Norstad, I., \& Asbjørnslett, B. E. (2013). Optimization, risk assessment and resilience in LNG transportation systems. Supply Chain Management: An International Journal, 18(3), $253-264$. http://doi.org/10.1108/SCM-03-2012-0109

Bosona, T. G., \& Gebresenbet, G. (2011). Cluster building and logistics network integration of local food supply chain. Biosystems Engineering, 108(4), 293-302.

Cabral, I., Grilo, A., \& Cruz-Machado, V. (2012). A decision-making model for Lean, Agile, Resilient and Green supply chain management. International Journal of Production Research, 50(17), 4830-4845. http://doi.org/10.1080/00207543.2012.657970

Chen, J. C., Cheng, C.-H., \& Huang, P. B. (2013). Supply chain management with lean production and RFID application: A case study. Expert Systems with Applications, 40(9), 3389-3397. http://doi.org/10.1016/j.eswa.2012.12.047

Childerhouse, P., Kang, Y., Huo, B., \& Mathrani, S. (2016). Enablers of supply chain integration: interpersonal and interorganizational relationship perspectives. Industrial Management \& Data Systems, 116(4), 838-855. http://doi.org/10.1108/IMDS-09-2015-0403

Christopher, M., \& Peck, H. (2004). Building the resilience supply chain. International Journal of Logistics Management, 15(2), 1-13. http://doi.org/10.1080/13675560600717763

Croxton, K. L. (2010). Ensuring Supply Chain Resilience: Development Of A Conceptual Framework, Journal Of Business Logistics, 31(1). http://doi.org/10.1002/j.2158-1592.2010.tb00125.x

Croxton, K. L., Pettit, T. J., Croxton, K. L., \& Fiksel, J. (2013). Ensuring Supply Chain Resilience : Development and Implementation of an Assessment Tool. Journal of Business Logistics. http://doi.org/10.1111/jbl.12009

Demmer, W. a., Vickery, S. K., \& Calantone, R. (2011). Engendering resilience in small- and medium-sized enterprises (SMEs): a case study of Demmer Corporation. International Journal of Production Research, 49(18), 5395-5413. http://doi.org/10.1080/00207543.2011.563903

DHL Trend Research. (2014). Self-Driving Vehicles in Logistics. Troisdorf.

Elleuch, H., Dafaoui, E., Elmhamedi, A., \& Chabchoub, H. (2016). Resilience and Vulnerability in Supply Chain: Literature review. IFAC, 49(12), 1448-1453. http://doi.org/10.1016/j.ifacol.2016.07.775

Esfahbodi, A., Zhang, Y., \& Watson, G. (2016). Sustainable supply chain management in emerging economies: Trade-offs between environmental and cost performance. International Journal of Production Economics, 1 17. http://doi.org/10.1016/j.ijpe.2016.02.013

Fang, W., Yeniyurt, S., Kim, D., and Cavusgil, S. T. (2006). The Impact of Information Technology on Supply Chain Capabilities and Firm Performance: A Resource-Based View. Industrial Marketing Management, 35(4), 493-504. https://doi.org/10.1016/j.indmarman.2005.05.003

Fakoor, A. M., Olfat, L., Feizi, K., \& Amiri, M. (2013). A Method for Measuring Supply Chain Resilience in the Automobile Industry. Journal of Basic and Applied Scientific Research (JBASR), 3(2), 537-544.

Fiksel, J. (2007). Sustainability and resilience: Toward a systems approach. IEEE Engineering Management Review, 35(3), 5. http://doi.org/10.1109/EMR.2007.4296420

Food and Agriculture Organization. (2015). How to Feed the World in 2050, Food and Agriculture Organization.

Gonçalves, M., \& Chicareli, R. L. (2014). Management capabilities in supply chain resilience, Federal Institute of Mato Grosso, Mato Grosso.

Gonzalez-Feliu, J., Morana, J., Grau, J. M. S., \& Ma, T. Y. (2013). Design and scenario assessment for collaborative logistics and freight transport systems. International Journal of Transport Economics, 40(2), 207-240.

Hefu, L., Ke, W., Kee Wei K., and Hua Z. (2013). "The Impact of IT Capabilities on Firm Performance: The Mediating Roles of Absorptive Capacity and Supply Chain Agility." Decision Support Systems, 54(3), 14521462.

Jüttner, U., \& Maklan, S. (2011). Supply chain resilience in the global financial crisis: an empirical study. Supply Chain Management: An International Journal, 16(4), 246-259. http://doi.org/10.1108/13598541111139062 
Kim, Y., Chen, Y.-S., \& Linderman, K. (2015). Supply network disruption and resilience: A network structural perspective. Journal of Operations Management, 33, 43-59. http://doi.org/10.1016/j.jom.2014.10.006

Klötzer, C., \& Pflaum, A. (2015). Cyber-Physical Systems ( CPS ) in Supply Chain Management - A definitional approach, The nordic logistics reaserch network conference.

Lau, H. C. (2014). Collaborative Urban Logistics - Challenges, Current Practices and Future Research. Singapore Management University, Singapore.

Leat, P., \& Revoredo-Giha, C. (2013). Risk and resilience in agri-food supply chains: the case of the ASDA PorkLink supply chain in Scotland. Supply Chain Management: An International Journal, 18(2), 219-231. http://doi.org/10.1108/13598541311318845

Lengnick-Hall, C. A., Beck, T. E., \& Lengnick-Hall, M. L. (2011). Developing a capacity for organizational resilience through strategic human resource management. Human Resource Management Review, 21(3), 243255. http://doi.org/10.1016/j.hrmr.2010.07.001

Liu, H., Ke, W., Wei, K. K., \& Hua, Z. (2013). The impact of IT capabilities on firm performance: The mediating roles of absorptive capacity and supply chain agility. Decision Support Systems, 54(3), 1452-1462. http://doi.org/10.1016/j.dss.2012.12.016

Mahdi, A., Vahid, K., \& Hamid, T. (2015). A new approach for supply chain risk management: Mapping SCOR into Bayesian network. Journal of Industrial Engineering and Management, 8(1).

Mensah, P., \& Merkuryev, Y. (2014). Developing a Resilient Supply Chain. Procedia - Social and Behavioral Sciences, 110, 309-319. http://doi.org/10.1016/j.sbspro.2013.12.875

Morrison-Saunders, A., \& Pope, J. (2013). Conceptualising and managing trade-offs in sustainability assessment. Environmental Impact Assessment Review, 38, 54-63. http://doi.org/10.1016/j.eiar.2012.06.003

Munoz, A., \& Dunbar, M. (2015). On the quantification of operational supply chain resilience. International Journal of Production Research, 53(22), 6736-6751. http://doi.org/10.1080/00207543.2015.1057296

Navickas, V., \& Gruzauskas, V. (2016). Big data concept in the food supply chain: Small markets case. Scientific Annals of Economics and Business, 63(1), 15-28. http://doi.org/10.1515/aicue-2016-0002

Nikookar, H., Takala, J., Sahebi, D., \& Kantola, J. (2014). A Qualitative Approach for Assessing Resiliency in Supply Chains. Management \& Production Engineering Review (MPER), 5(4), 36-45. http://doi.org/10.2478/mper-2014-0034

Parfitt, J., Barthel, M., \& Macnaughton, S. (2010). Food waste within food supply chains: quantification and potential for change to 2050. Philosophical Transactions of the Royal Society of London. Series B, Biological Sciences, 365(1554), 3065-81. http://doi.org/10.1098/rstb.2010.0126

Park, K. (2011). Flexible and Redundant Supply Chain Practices to Build Strategic Supply Chain Resilience: Contingent and Resource-based Perspectives. Toledo.

Pettit, T. J., Croxton, K. L., \& Fiksel, J. (2013). Ensuring Supply Chain Resilience: Development and Implementation of an Assessment Tool. Journal of Business Logistics, 34(1), 46-76. http://doi.org/10.1111/jbl.12009

Ponis, S. T., \& Koronis, E. (2012). Supply Chain Resilience: Definition Of Concept And Its Formative Elements, The Journal of Applied Business Research, 28(5), 921-930. http://doi.org/10.19030/jabr.v28i5.7234

Prajogo, D., \& Olhager, J. (2012). Supply chain integration and performance: The effects of long-term relationships, information technology and sharing, and logistics integration. International Journal of Production Economics, 135(1), 514-522. http://doi.org/10.1016/j.ijpe.2011.09.001

Proper. (2011). How to manage Resilience in Public Transport Organizations, Netherlands Environmental Assessment Agency, Antwerpen.

Seuring, S. (2013). A review of modeling approaches for sustainable supply chain management. Decision Support Systems, 54(4), 1513-1520. http://doi.org/10.1016/j.dss.2012.05.053

Soni, U., Jain, V., \& Kumar, S. (2014). Measuring supply chain resilience using a deterministic modeling approach. Computers \& Industrial Engineering, 74, 11-25. http://doi.org/10.1016/j.cie.2014.04.019

Spiegler, V. L. M., Naim, M. M., \& Wikner, J. (2012). A control engineering approach to the assessment of supply chain resilience. International Journal of Production Research, 50(21), 6162-6187. http://doi.org/10.1080/00207543.2012.710764

Winn M., Pinkse, J., IllgeStudies, F. (2012)., Case Studies on Trade-Offs in Corporate Sustainability, Corporate Social Responsibility and Environmental Management, 19(2). DOI: 10.1002/csr.293

Swafford, P. M., Ghosh, S., \& Murthy, N. (2008). Achieving supply chain agility through IT integration and flexibility. International Journal of Production Economics, 116(2), 288-297. http://doi.org/10.1016/i.ijpe.2008.09.002

Verdouw, C. N., Wolfert, J., Beulens, A. J. M., \& Rialland, A. (2015). Virtualization of food supply chains with the internet of things. Journal of Food Engineering, 176, 128-136. http://doi.org/10.1016/j.jfoodeng.2015.11.009 
Wang, G., Gunasekaran, A., Ngai, E. W. T., \& Papadopoulos, T. (2016). Big data analytics in logistics and supply chain management: Certain investigations for research and applications. International Journal of Production Economics, 176, 98-110. http://doi.org/10.1016/j.ijpe.2016.03.014

Wieland, A., \& Wallenburg, C. M. (2013). The influence of relational competencies on supply chain resilience: A relational view. International Journal of Physical Distribution \& Logistics Management, 43(4), 300-320. http://doi.org/10.1108/IJPDLM-08-2012-0243

Wu, F., Yeniyurt, S., Kim, D., \& Cavusgil, S. T. (2006). The impact of information technology on supply chain capabilities and firm performance: A resource-based view. Industrial Marketing Management, 35(4), 493-504. http://doi.org/10.1016/j.indmarman.2005.05.003

Zhao, R., Liu, Y., Zhang, N., \& Huang, T. (2016). An optimization model for green supply chain management by using a big data analytic approach, Journal of Cleaner Production, 142(2), 1085-1097. https://doi.org/10.1016/i.jclepro.2016.03.006

Zobel, C. W., \& Cook, D. (2008). A Decision Support Framework to Assess Supply Chain Resilience. Framework, Proceeding (May 2008), 596-605. Retrieved from http://www.iscram.org/dmdocuments/ISCRAM2008/papers/ISCRAM2008_Falasca_etal.pdf

\section{AUTHORS' SHORT BIOGRAPHIES}

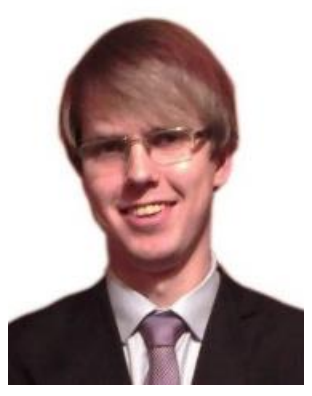

Valentas Gružauskas received bachelor degree in "applied mathematics and economics" in in 2014, master degree in "industrial engineering and management" in 2016 and since September, 2016 started studying PhD in management science. The main research area is operation research in logistics with a focus on logistic cluster development and innovative technology usage. Due to mathematical background, Gružauskas focuses on quantitative analysis by conducting simulations, stochastic and dynamic models and other analytical approaches to amplify the developed theories. Gružauskas also is working as a freelance data analyst with a focus on statistical analysis, web scraping, machine learning.

Author's contact data: Kaunas University of Technology

E-mail: Valentas.gruzauskas@ktu.lt

Linkedin: lt.linkedin.com/in/valentasgruzauskas

ResearchGate: Valentas_Gruzauskas

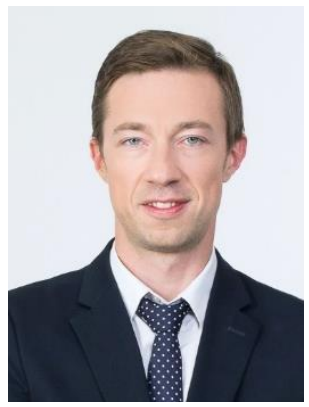

Mantas Vilkas is an associate professor in the Department of Management, School of Economics and Business, Kaunas University of Technology. His current research focuses on practice theory, specifically in theory of organizational routines. He also studies the mechanisms of diffusion and effects of operations management methods for manufacturing organizations.

Author's contact data: K. Donelaičio g. 73, LT-44249 Kaunas

E-mail: mantas.vilkas@ktu.lt 